\title{
Thymic hypoplasia due to congenital rubella
}

\author{
APARECIDA G. P. GARCIA, FERNANDO OLINTO, and TEREZINHA G. O. FORTES \\ From the Department of Pathology, Instituto Fernandes Figueira, Rio de Janeiro, Brazil
}

Garcia, A. G. P., Olinto, F., and Fortes, T. G. O. (1974). Archives of Disease in Childhood, 49, 181. Thymic hypoplasia due to congenital rubella. Two cases of rubella embryopathy are presented. In both, hypoplasia of the thymus and of the thymus-dependent lymphoid tissue was conspicuous. Vascular lesions identical with those described in the congenital rubella syndrome were present in the thymic vessels. The coexistence of these vascular and parenchymatous lesions in the thymus suggests that the rubella virus may be the aetiological agent responsible for this type of immune deficiency disease.

Congenital rubella has been considered as sometimes leading to immunological deficiency associated with the histological abnormalities that are to be seen in the thymus, spleen, and lymph nodes (Seligmann, Fudenberg, and Good, 1968; Plotkin, Klaus, and Whitely, 1966; Hancock, Huntley, and Sever, 1968; Singer et al., 1969). We have had the opportunity to study two fatal cases of rubella embryopathy, where there was a combination of both the thymic hypoplasia and the vascular thymic lesions, as described by Campbell (1965) and Esterly and Oppenheimer $(1967,1969)$ in congenital infection by the rubella virus.

\section{Methods}

The material was fixed in $10 \%$ formalin and the slides were stained with haematoxylin and eosin. Selected tissues were stained with periodic acid Schiff (PAS) for mucopolysaccharides; von Kossa reaction for calcium; Perl's for iron; Gomori's one-step trichrome for collagen; and orcein for elastic tissue.

\section{Case reports}

Case 1. A white male, 2 months of age, born at term $2650 \mathrm{~g}$ ) by normal delivery. He was the product of a pregnancy complicated by rubella in the first trimester. The maternal rubella antibodies (HI) were positive (1/160) 4 years after the birth of the child. An imperforate anus led to a colostomy being made on the first day of life. Death occurred at 2 months.

Pathological findings. Necropsy examination showed the following. Weight $2800 \mathrm{~g}$ (normal $4050 \mathrm{~g}$ ), length $51 \mathrm{~cm}$ (normal $54 \mathrm{~cm}$ ). Thymus $1 \mathrm{~g}$ (normal $9 \cdot 3 \mathrm{~g}$ ). Heart showed persistent ductus arteriosus, pulmonary

Received 7 August 1973. atresia, hypoplastic right ventricle, tricuspid stenosis, atrial and ventricular septal defects. A papillomatous nodule was prominent in the interventricular orifice (Fig. 1). The liver was large, weighing $138 \mathrm{~g}$ (normal $127 \mathrm{~g}$ ), with a mottled aspect. The spleen appeared enlarged. Cystic dysplasia of the left kidney and ureteric atresia were present. The brain showed whitish meningeal plaques, dilated ventricles, thickening of the ependyma, and sponginess of the white matter.

Microscopical examination. Thymus consisted of a small number of immature lobules separated by relatively thick fibrous septa, where numerous hamartomatous congested vessels were seen, encircled by adipose tissue. The cells making up the lobules were reticuloepithelial, with elongated or round vesicular nuclei containing a distinct chromatin pattern and rather indefinite cytoplasmic boundaries. Differentiation of the lobule into cortex and medulla was almost entirely absent, and only a

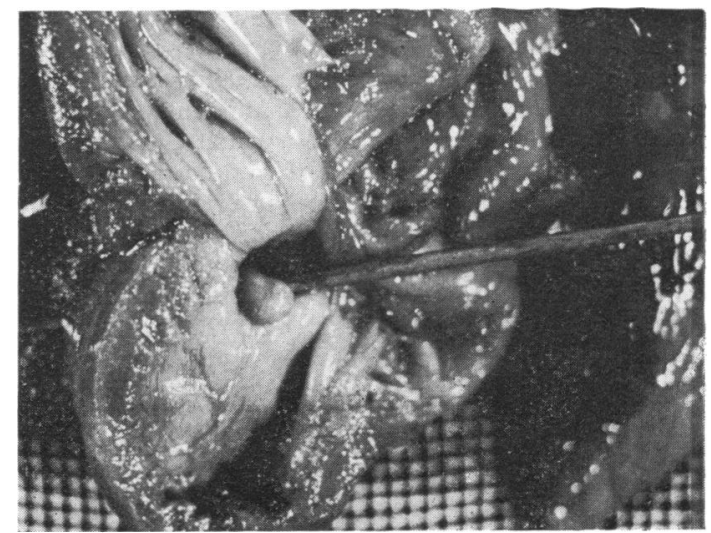

FIG. 1.-Case 1. Papillomatous nodule in the interventricular orifice. 


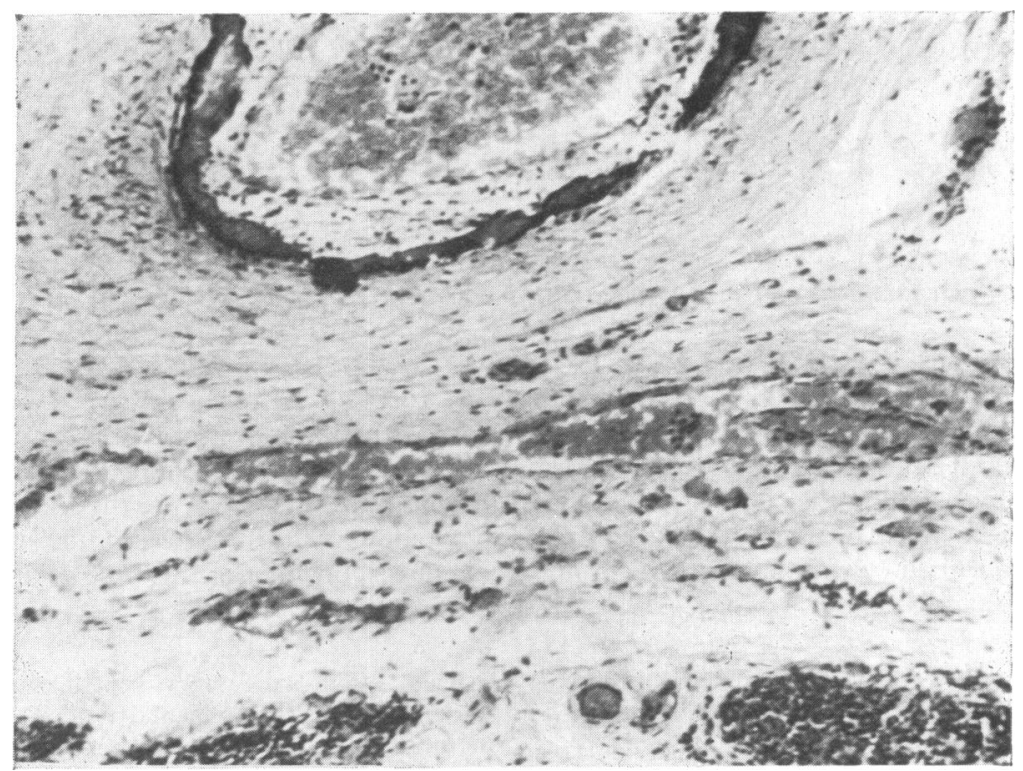

FIG. 2.-Case 1. Thymic artery. Note fibrous proliferation of the intima and deposition of homogeneous dark material in the media. (H. and $E$. $\times 125$.)

few lymphocytes were seen in the central portion. Hassall's bodies were absent from the majority of lobules, and were calcified or cystic in others. One enormous and abnormal Hassall's body was seen, encircled by a thin rim of thymic tissue. The arteries showed fibrous proliferation of intima, irregularity of the elastic membranes, and deposition of homogeneous material, staining by the Schiff periodic acid, von Kossa, and Perl's methods (Fig. 2).

Lymph glands. In the subcapsular sinus only a few lymphocytes and macrophages were seen. The follicular nodes consisted of small and ill-defined germinal centres bounded by thin lymphocytic cuff; absence of plasmocytes. The thymus-dependent areas were devoid of lymphocytes, being mainly occupied by reticular cells. Spleen presented a uniform aspect due to paucity of malpighian corpuscles, which consisted of a germinal centre and a thin cuff of lymphocytes.

Intestines and appendix. The lymphoid tissue in the mucosa was entirely lacking, except for a few widelyspaced small foci of lymphocytes in some of the Peyer's patches. Liver showed cholestasis, histiocytic nodules, hypertrophy of Kupffer's cells. Heart. Some of the coronary vessels presented fibrous proliferation of the intima. In the adjacent myocardial areas the fibres were replaced by fibrous tissue. Necrotic focal myocarditis was also seen. The papillomatous node of the ventricular orifice consisted of paucicellular fibrous tissue with areas of fibrinoid degeneration. Aorta showed fragmentation and disorganization of the elastic fibres in the subintima. Kidneys. Cystic hypoplasia of the left; acute pyelonephritis and membranous glomerulopathy.
Right adrenal showed extensive areas of necrosis, surrounded by calcification and fibrous proliferation.

Lungs showed interstitial pneumonia; in the main branches of the pulmonary artery were vascular lesions identical with those described in the thymus (Fig. 3). Brain showed chronic proliferative meningitis. In the meningeal, intrinsic arteries, and in the veins of the grey matter there was destruction of one or more layers of the vessel wall with replacement of the tissue by granular material having the same characteristics as that deposited in the blood vessels of the thymus and lungs. Foci of tissue necrosis associated with the vascular lesions were noted.

Case 2. A white male, born at term $(2900 \mathrm{~g})$ by normal delivery. Maternal rubella was clinically diagnosed in the first month of pregnancy and therapeutic abortion suggested. From birth there were bouts of cyanosis and dyspnoea. When examined at age 18 months he weighed $5675 \mathrm{~g}$ (normal 11,000 g), with a length of $73 \mathrm{~cm}$ (normal $81 \mathrm{~cm}$ ). There was bilateral cataract, cleft palate, deformities of cranium and thorax, and a cardiac murmur. Blood pressure $75 / 45 \mathrm{mmHg}$. The liver was enlarged. The fingers were clubbed. He died aged 22 months.

Pathological findings. At necropsy the body weighed $4900 \mathrm{~g}$ (normal $11,920 \mathrm{~g}$ ), with a length of $75 \mathrm{~cm}$ (normal $85.4 \mathrm{~cm}$ ), and exhibited the somatic abnormalities already described. Thymus was reduced to a whitish small tissue. Lungs were mottled, voluminous, with abnormal lobulation of the left. Heart and great vessels 


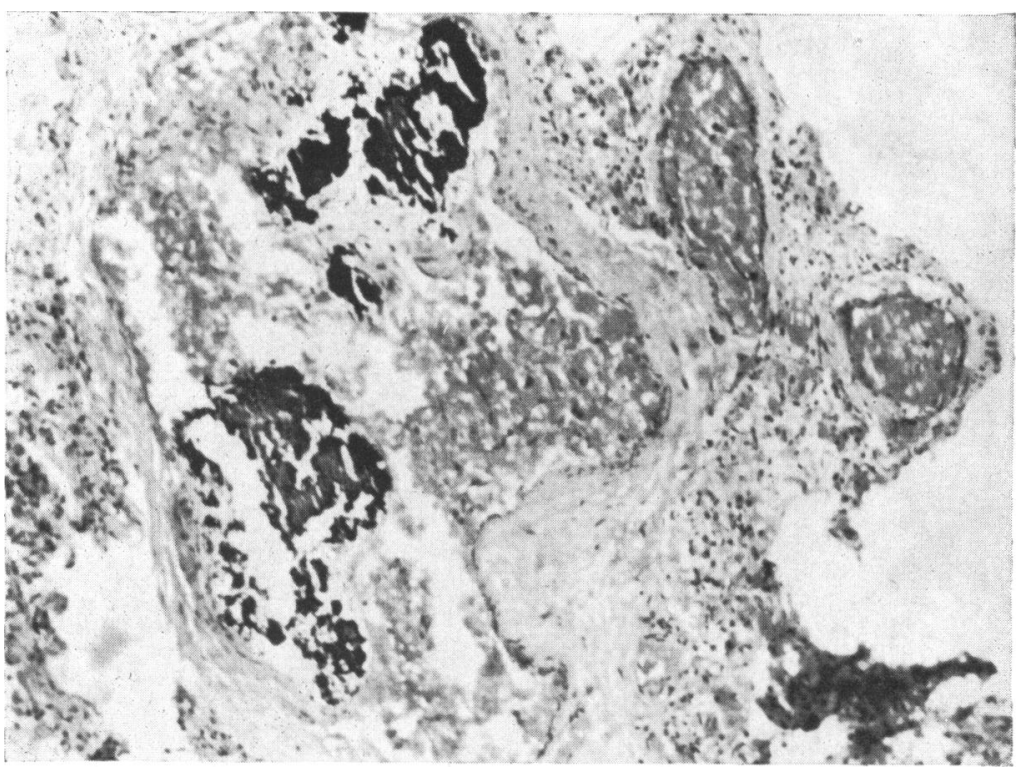

FIG. 3.- Case 1. Pulmonary artery. Fibrous proliferation of the intima and deposition of dark material in the lumen. (H. and $E . \quad \times 125$.)

showed persistent ductus arteriosus $(1 \mathrm{~cm}-0.8 \mathrm{~cm})$; abnormal left subclavian implantation. Liver weighed $325 \mathrm{~g}$ (normal $380 \mathrm{~g}$ ) and had a mottled aspect on section. Spleen weighed $17 \mathrm{~g}$ (normal $33 \mathrm{~g}$ ), dark red uniform appearance of the pulp. Brain weighed $760 \mathrm{~g}$ (normal $1059 \mathrm{~g}$ ), no abnormalities were noted.

Microscopical examination. Thymus was formed by abnormal or primitive lobules with bizarre edges, set in abundant fibrous and adipose tissue. The lobules were paucicellular containing reticuloepithelial cells, a few lymphocytes, and occasional calcified Hassall's bodies (Fig. 4). Some arterial branches showed an irregular lumen, distorted medial muscular, fragmentation of internal elastic membrane, and endothelial 'cushions' (Fig. 5). Lymph node. Occasional mononuclear cells

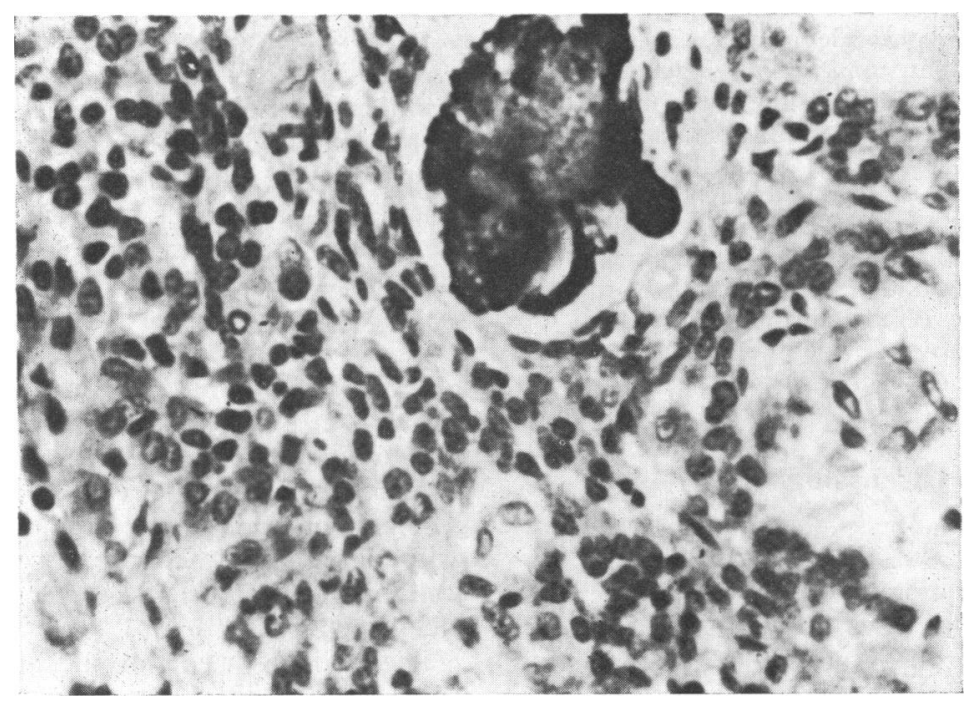

FIG. 4.-Case 2. Thymus. Lobule containing reticuloepithelial cells, scanty lymphocytes, and calcified Hassall's bodies. (H. and $E . \quad \times 494$.) 


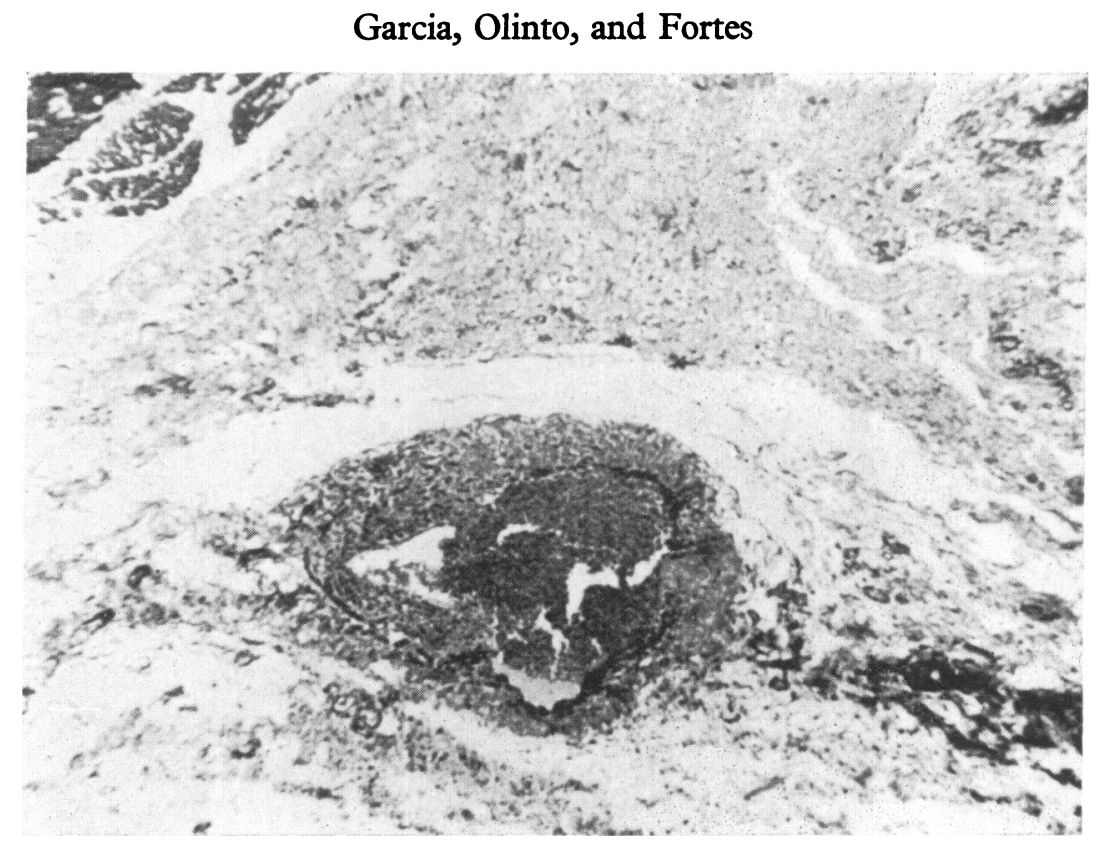

FIG. 5.-Case 2. Thymus. Artery exhibiting irregular lumen, distorted medial muscular fragmentation of internal elastic and endothelial cushions. (Gomori. $\times 125$.)

were identifiable in the peripheral sinus; there was an absence of lymphocytes in the paracortical and perifollicular areas. Spleen. The follicle formation was scarcely visible; splenic lymphocytes were conspicuously decreased and the usual periarterial cuffing was absent. Similar changes were noted in other lymphoid tissues, i.e., Peyer's patches of the intestines and appendix. In the intestinal mucosa a few plasmocytes were seen.

Kidneys showed membranous glomerulopathy, cortical glomerulosclerosis, nephrocalcinosis, and interstitial mononuclear infiltration. Lungs. The main pulmonary arteries showed fibrous proliferation of the intima with irregularity of the internal elastic lamina; chronic inflammatory infiltrates and thickening of the alveolar septa were seen, with hyaline membranes in the alveoli. Brain showed chronic proliferative leptomeningitis, with deposits of amorphous material, haematoxylin- and PAS-positive in the vessels. In the vessels of the grey nuclei, white matter, cerebellum, and brain stem, the same vascular lesions were evident, and in the adjacent areas there were foci of disintegration.

\section{Discussion}

Seligmann et al. (1968) considered that intrauterine environmental factors can affect the development of the immunological functions and so cause immunological deficiencies. Plotkin et al. (1965) suggested that the rubella virus may interfere with the development of the thymus and lymph nodes. Soothill, Hayes, and Dudgeon (1966) confirmed the high incidence of hypo- $\gamma$-globulinaemia in the congenital rubella syndrome, suggesting a causal relation.

In the present cases a rubella embryopathy with multiple malformations was associated with vascular and visceral lesions attributable to congenital infection by the rubella virus (Campbell, 1965; Esterly and Oppenheimer, 1967, 1969; Rorke and Spiro, 1967; Phelan and Campbell, 1969; Korones et al., 1965; Strauss and Bernstein, 1968; Plotkin et al., 1965). In both cases the microscopical examination showed hypoplasia of the thymus and of the thymus-dependent lymphoid tissue. In the vessels of the thymus, lesions identical to those described in the rubella syndrome were present. In the light of the many other manifestations of the rubella syndrome in these patients, it is likely that the thymic hypoplasia also was attributable to intrauterine rubella infection.

Bellanti et al. (1965) were able to isolate the rubella virus in high concentration from the lymphoreticular system. As Simons (1968) has emphasized, the rubella virus may cause specific or general, permanent or temporary damage to lymphoid tissue, in conformity with the variety of immunological deficiencies seen in the congenital rubella syndrome.

The nodular lesion in the orifice of the interventricular cardiac septum is of interest, as it is identical with the valvular cardiac lesions described by Singer et al. (1967) in congenital rubella. 
We are indebted to our librarian, Giselda Fonseca Lima, for help with references. This study was supported by a grant from Conselho Nacional de Pesquisa (CNPq).

\section{REFERENCES}

Bellanti, J. A., Artenstein, M. S., Olson, L. C., Buescher, E. L. Luhrs, C. E., and Milstead, K. L. (1965). Congenital rubella -clinicopathologic, virologic and immunologic studies. American Fournal of Diseases of Children, 110, 464.

Campbell, P. E. (1965). Vascular abnormalities following maternal rubella. British Heart fournal, 27, 134.

Esterly, J. R., and Oppenheimer, E. H. (1967). Vascular lesions in infants with congenital rubella. Circulation, 36, 544.

Esterly, J. R., and Oppenheimer, E. H. (1969). Pathological lesions due to congenital rubella. Archives of Pathology, 87, 380.

Hancock, M. P., Huntley, C. C., and Sever, J. L. (1968). Congenital rubella syndrome with immunoglobulin disorder. Fournal of Pediatrics, 72, 636.

Korones, S. B., Ainger, L. E., Monif, G. R. G., Roane, J., Sever, J. L., and Fuste, F. (1965). Congenital rubella syndrome. New clinical aspects with recovery of virus from affected infants. fournal of Pediatrics, 67, 166.

Phelan, P., and Campbell, P. (1969). Pulmonary complications of rubella embryopathy. Fournal of Pediatrics, 75, 202.

PJotkin, S. A., Klaus, R. M., and Whitely, J. P. (1966). Hypogammaglobulinemia in an infant with congenital rubella syndrome; failure of 1-adamantanamine to stop virus excretion. fournal of Pediatrics, 69, 1085.
Plotkin, S. A., Oski, F. A., Hartnett, E. M., Hervada, A. R., Friedman, S., and Gowing, J. (1965). Some recently recognized manifestations of the rubella syndrome. Fournal of Pediatrics, 67, 182.

Rorke, L. B., and Spiro, A. J. (1967). Cerebral lesions in congenital rubella syndrome. Fournal of Pediatrics, 70, 243.

Seligmann, M., Fudenberg, H. H., and Good, R. A. (1968). Editorial. A proposed classification of primary immunologic deficiencies. American fournal of Medicine, 45, 817.

Simons, M. J. (1968). Congenital rubella: an immunological paradox? Lancet, 2, 1275.

Singer, D. B., Rudolph, A. H., Rosenberg, H. S., Rawls, W. B., and Bonior, M. (1967). Pathology of the congenital rubella syndrome. Fournal of Pediatrics, 71, 665.

Singer, D. B., South, M. A., Montgomery, J. R., and Rawls, W. E. (1969). Congenital rubella syndrome-lymphoid tissue and immunologic status. American fournal of Diseases of Children, 118, 54.

Soothill, J. F., Hayes, K., and Dudgeon, J. A. (1966). The immunoglobulins in congenital rubella. Lancet, $1,1385$.

Strauss, L., and Bernstein, J. (1968). Neonatal hepatitis in congenital rubella-a histopathological study. Archives of Pathology, 86, 317.

Correspondence to Dr. A. G. P. Garcia, Institute Fernandes Figueira, Av. Ruy Barbosa 716, Rio de Janeiro, Brazil. 